\title{
Contribution of $\mathrm{Ca}^{2+}$-Dependent $\mathrm{Cl}^{-}$Channels to Norepinephrine-Induced Contraction of Femoral Artery Is Replaced by Increasing EDCF Contribution during Ageing
}

\author{
Silvia Liskova, ${ }^{1,2}$ Miriam Petrova, ${ }^{2}$ Petr Karen, ${ }^{1}$ Michal Behuliak, ${ }^{1}$ and Josef Zicha ${ }^{1}$ \\ ${ }^{1}$ Institute of Physiology, Academy of Sciences of the Czech Republic, 14220 Prague 4, Czech Republic \\ ${ }^{2}$ Institute of Pharmacology, Faculty of Medicine, Comenius University, Bratislava, Slovakia \\ Correspondence should be addressed to Silvia Liskova; silvia.liskova@gmail.com
}

Received 27 November 2013; Accepted 16 January 2014; Published 23 February 2014

Academic Editor: Iveta Bernatova

Copyright (c) 2014 Silvia Liskova et al. This is an open access article distributed under the Creative Commons Attribution License, which permits unrestricted use, distribution, and reproduction in any medium, provided the original work is properly cited.

\begin{abstract}
The activation of $\mathrm{Ca}^{2+}$-dependent $\mathrm{Cl}^{-}$channels during norepinephrine-induced contraction of vascular smooth muscle was suggested to depolarize cell membrane and to increase $\mathrm{Ca}^{2+}$ entry. Hypertension and ageing are associated with altered $\mathrm{Ca}^{2+}$ handling including possible activation of $\mathrm{Ca}^{2+}$-dependent $\mathrm{Cl}^{-}$channels. Our study was aimed to determine $\mathrm{Ca}^{2+}$-dependent $\mathrm{Cl}^{-}$channels contribution to norepinephrine-induced contraction during hypertension and ageing. Norepinephrine-induced concentration-response curves of femoral arteries from 6- and 12-month-old spontaneously hypertensive rats (SHR) and WistarKyoto (WKY) rats were recorded using wire myograph. Pretreatment with $\mathrm{Ca}^{2+}$-dependent $\mathrm{Cl}$ - channel inhibitor indanyloxyacetic acid 94 [R(+)-IAA-94](IAA) attenuated norepinephrine-induced contraction in all groups, but relatively more in WKY than SHR arteries. The attenuation of norepinephrine-induced contraction after $\mathrm{Ca}^{2+}$-dependent $\mathrm{Cl}^{-}$channels blockade was partially reduced in 12-month-old WKY rats, but substantially diminished in 12-month-old SHR. IAA effect was enhanced after NO synthase inhibition but decreased by ageing. In 20-month-old WKY rats norepinephrine-induced contraction was not affected by IAA but was almost abolished after cyclooxygenase inhibition by indomethacin or niflumic acid. In conclusion, contribution of $\mathrm{Ca}^{2+}$-dependent $\mathrm{Cl}^{-}$channels to norepinephrine-induced contraction diminished with age, hypertension development, and/or NO synthesis inhibition. $\mathrm{Ca}^{2+}$-dependent $\mathrm{Cl}^{-}$channels are important for maintenance of normal vascular tone while their inactivation/closing might be a pathological mechanism.
\end{abstract}

\section{Introduction}

The stimulation of vascular smooth muscle cells with norepinephrine leads to the release of $\mathrm{Ca}^{2+}$ from intracellular $\mathrm{Ca}^{2+}$ stores through $\mathrm{IP}_{3}$ pathway (phasic contraction) and thereafter to $\mathrm{Ca}^{2+}$ influx through the opening of L-type voltagedependent $\mathrm{Ca}^{2+}$ channels (L-VDCC) (tonic contraction). The link between the opening of $\mathrm{Ca}^{2+}$ stores and L-VDCC could be mediated either through the elevation of intracellular $\mathrm{Ca}^{2+}\left[\mathrm{Ca}^{2+}\right]_{i}$ levels or might involve other mechanisms such as opening of $\mathrm{Cl}^{-}$channels or closure of $\mathrm{K}^{+}$channels [13]. Brayden and Nelson [4] showed that pressure-induced contraction of vascular smooth muscle is mediated by $\mathrm{Ca}^{2+}$ influx through L-VDCC and is modulated by a negative feedback pathway involving activation of large-conductance
$\mathrm{Ca}^{2+}$-dependent $\mathrm{K}^{+}$channels. We demonstrated that these $\mathrm{K}^{+}$channels play an important role in modulating vascular contraction in spontaneous hypertension [5]. Calculated equilibrium potential for $\mathrm{Cl}^{-}$in vascular cells is $-26 \mathrm{mV} \mathrm{[6],}$ which is high enough to activate L-VDCC [7]. Furthermore, $\mathrm{Ca}^{2+}$-dependent $\mathrm{Cl}^{-}$channels play a role in $\mathrm{Ca}^{2+}$ uptake to sarcoplasmic reticulum in smooth muscle because the administration of $\mathrm{Cl}^{-}$channel blockers NPPB (5-nitro-2(3-phenylpropylamino)benzoic acid) and IAA (indanyloxyacetic acid $94(\mathrm{R}(+)$-IAA-94) almost completely blocked the $\mathrm{Ca}^{2+}$ uptake [8]. It is evident that $\mathrm{Cl}^{-}$conductance is activated by the enhancement of either $\mathrm{Ca}^{2+}$ release from $\mathrm{Ca}^{2+}$ stores or $\mathrm{Ca}^{2+}$ influx [9]. The $\mathrm{Ca}^{2+}$-dependent $\mathrm{Cl}^{-}$channels exist in two states, open and closed, with a relatively long mean open time. Some of the agents that inhibit $\mathrm{Ca}^{2+}$-dependent 
$\mathrm{Cl}^{-}$channels interact directly with the open channel, which suggests that the most likely role of $\mathrm{Ca}^{2+}$-dependent $\mathrm{Cl}^{-}$ channels in smooth muscle is to produce membrane depolarization and contraction to neurotransmitters [10]. Therefore norepinephrine-induced contraction, which involves the increase of both $\mathrm{Ca}^{2+}$ release from $\mathrm{Ca}^{2+}$ stores and $\mathrm{Ca}^{2+}$ influx should be altered by the blockade of $\mathrm{Ca}^{2+}$-dependent $\mathrm{Cl}^{-}$channels. It has been shown that $\mathrm{Ca}^{2+}$-dependent $\mathrm{Cl}^{-}$ channels play a major role in the response to norepinephrine in the portal vein [9] and mesenteric vein [11] or in the response of coronary and mesenteric arteries to endothelin [12]. Chloride channel blockers markedly attenuate both rapid and sustained responses of angiotensin II-induced contraction of renal vascular smooth muscle cells and thus contribute to, rather than being the consequence of, the initial rapid contractile response [13]. Pacaud et al. [14] suggested that the activation of $\mathrm{Cl}^{-}$channels by $\mathrm{Ca}^{2+}$ release from intracellular stores might determine the maximal contraction by influencing the magnitude of membrane depolarization during agonist-induced contraction.

The activation of $\mathrm{Ca}^{2+}$-dependent $\mathrm{Cl}^{-}$channels in aortic smooth muscle cells occurs after caffeine-induced $\mathrm{Ca}^{2+}$ release without $\mathrm{Ca}^{2+}$ influx, but the repetitive activation of $\mathrm{Cl}^{-}$channels depends on $\mathrm{Ca}^{2+}$ influx through L-VDCC. Moreover, the progressive disappearance of caffeine-induced $\mathrm{Ca}^{2+}$ release and $\mathrm{Ca}^{2+}$-dependent $\mathrm{Cl}^{-}$currents in smooth muscle cells treated with $\mathrm{NO}$ donors could result from NOinduced inhibition of ryanodine- and caffeine-sensitive $\mathrm{Ca}^{2+}$ channels and/or L-VDCC [15]. This mechanism could be more important for L-NAME-induced contraction of rat coronary arteries, because the changes of $\mathrm{Cl}^{-}$conductance are involved in the L-NAME-induced contraction and the blockade of $\mathrm{Cl}^{-}$channels abolished the L-NAME-induced contractions [16]. On the other hand, there are still confusing results about the involvement of endothelium in the effect of $\mathrm{Cl}^{-}$channel activation. Using small mesenteric arteries Matchkov et al. [17] and Boedtkjer et al. [18] showed that there is a $\mathrm{Cl}^{-}$current which is dependent on $\mathrm{Ca}^{2+}$ and cGMP and that the NO is necessary for the activation of this current, which leads to vasomotion and can participate in smooth muscle cell synchronization. This $\mathrm{Ca}^{2+}$-dependent and cGMP-dependent $\mathrm{Cl}^{-}$current is sensitive to $\mathrm{Zn}^{2+}$ ions but less sensitive to conventional $\mathrm{Cl}^{-}$channel blockers.

There are numerous reports on altered vascular function in hypertension and/or ageing in rats (for review see [19]). These alterations involve impaired endotheliumdependent vascular relaxation due to the attenuated vasodilation induced by nitric oxide $[20,21], \beta$-adrenoceptor stimulation $[22,23]$, changes in $\mathrm{Ca}^{2+}$ entry and cell $\mathrm{Ca}^{2+}$ handling $[24,25]$, and so forth. Prominent role of $\mathrm{Ca}^{2+}$ influx through L-VDCC in the control of vascular tone and blood pressure can be demonstrated both under the in vivo and in vitro conditions as we have previously reported in conscious SHR and their isolated femoral arteries [26-28].

Our aim was to quantify the changes in $\mathrm{Ca}^{2+}$-dependent $\mathrm{Cl}^{-}$channel-sensitive component of norepinephrine-induced contraction during the ageing and hypertension. Our hypothesis was that norepinephrine-stimulation of vascular smooth muscle opens/activates $\mathrm{Ca}^{2+}$-dependent $\mathrm{Cl}^{-}$channels in SHR vessels to a larger extent than in those of WKY. The NO synthase inhibition was used to augment the magnitude of norepinephrine-induced contraction as well as to modify the contribution of the above ion channels to this contraction. IAA was used to inhibit $\mathrm{Ca}^{2+}$-dependent $\mathrm{Cl}^{-}$channels in femoral arteries isolated from four groups of rats-adult WKY rats, aged WKY rats, adult SHR, and aged SHR. The second aim of our study was to compare the contribution of $\mathrm{Ca}^{2+}$-dependent $\mathrm{Cl}^{-}$channels and endothelium-derived constricting factor (EDCF) to norepinephrine-induced contraction (including their age-dependent changes). This was possible to examine only in femoral arteries because EDCF is produced in femoral but not in small mesenteric arteries [29]. We investigated femoral arteries of 20-month-old WKY rats after the blockade of $\mathrm{Ca}^{2+}$-dependent $\mathrm{Cl}^{-}$channels by IAA and after the inhibition of cyclooxygenase by indomethacin, which is the main enzyme producing endothelium-derived constricting factor (EDCF).

\section{Material and Methods}

2.1. General Procedure. Wistar-Kyoto (WKY) rats and spontaneously hypertensive rats (SHR) were sacrificed at the age of 6 months (adult WKY rats and adult SHR) and 12 months (aged WKY rats and aged SHR rats). The second series of experiments was carried out in 20-month-old WKY rats. Animals were housed under standard laboratory conditions (temperature $23 \pm 1^{\circ} \mathrm{C}, 12 \mathrm{~h}$ light-dark cycle, pelleted ST-1 diet, and tap water ad libitum). All procedures and experimental protocols, which were approved by the Ethical Committee of the Institute of Physiology, Academy of Sciences of Czech Republic, conform to the European Convention on Animal Protection and Guidelines on Research Animal Use.

Animals were anesthetized with ether and blood pressure was measured directly by the puncture of carotid artery. The animals were killed by overdose of $\mathrm{CO}_{2}$ and after decapitation femoral arteries with intact endothelium were cut into $2 \mathrm{~mm}$ long segments and placed in a MulvanyHalpern isometric myograph (M 510A, DMT, Denmark). The myograph chamber was filled with modified Krebs-Henseleit solution $\quad\left(119 \mathrm{mM} \mathrm{NaCl}, 4.7 \mathrm{mM} \mathrm{KCl}, 1.17 \mathrm{mM} \mathrm{MgSO}_{4}\right.$, $25 \mathrm{mM} \mathrm{NaHCO}_{3}, \quad 1.18 \mathrm{mM} \mathrm{KH}_{2} \mathrm{PO}_{4}, \quad 2.5 \mathrm{mM} \mathrm{CaCl}_{2}, \quad 2 \mathrm{~g} / \mathrm{L}$ glucose, $37^{\circ} \mathrm{C}$ ) and bubbled with $95 \% \mathrm{O}_{2}$ and $5 \% \mathrm{CO}_{2}$. The inner arterial diameter was set to be $90 \%$ of the diameter predicted for the pressure of $100 \mathrm{~mm} \mathrm{Hg}$ in the wire myograph. During $30 \mathrm{~min}$ of stabilization the vessels were left to achieve their basal tone. To provide the maximal depolarization-induced contraction vessels were incubated with a depolarizing solution (modified Krebs-Henseleit solution with $124 \mathrm{mM} \mathrm{K}^{+}$but without $\mathrm{Na}^{+}$).

2.2. Experimental Protocol: The Role of $\mathrm{Ca}^{2+}$-Dependent $\mathrm{Cl}^{-}$Channel in Norepinephrine-Induced Contraction. The femoral arteries isolated from adult and aged WKY rats and SHR were studied in the first part of our experiments. Subsequent arterial contractions were induced by cumulative doses of norepinephrine $\left(3.10^{-8}\right.$ to $\left.10^{-4} \mathrm{~mol} / \mathrm{L}\right)$ 
and then acetylcholine-induced relaxations $\left(3.10^{-8} \mathrm{~mol} / \mathrm{L}\right.$ and $10^{-6} \mathrm{~mol} / \mathrm{L}$ or $3.10^{-6} \mathrm{~mol} / \mathrm{L}$ ) of norepinephrine-precontracted vessels were measured. One segment with preserved endothelium was studied in each rat. After repeated washing and stabilization of basal tone norepinephrine-induced concentration-response curves were again determined in the same artery segment in the presence of NO synthase inhibitor $\mathrm{N}^{\omega}$-nitro-L-arginine (L-NNA, $10^{-4} \mathrm{~mol} / \mathrm{L}$, preincubation time $15 \mathrm{~min}$ ) or in the presence of $\mathrm{Ca}^{2+}$-dependent $\mathrm{Cl}^{-}$channel blocker indanyloxyacetic acid 94 (R(+)-IAA94, IAA, $10^{-5} \mathrm{~mol} / \mathrm{L}$, preincubation time $\left.10 \mathrm{~min}\right)$. Finally, these concentration-response curves were measured in the presence of both inhibitors L-NNA and IAA.

2.3. Experimental Protocol: The Changes of $\mathrm{Ca}^{2+}$-Dependent $\mathrm{Cl}^{-}$Channels and EDCF during Ageing. In the second part of our study we used femoral arteries isolated from 20month-old WKY rats. Arterial contraction induced by cumulative doses of norepinephrine $\left(10^{-8}\right.$ to $\left.10^{-4} \mathrm{~mol} / \mathrm{L}\right)$ followed by arterial relaxation elicited by acetylcholine application $\left(10^{-8} \mathrm{~mol} / \mathrm{L}\right.$ and $\left.10^{-6} \mathrm{~mol} / \mathrm{L}\right)$ were first measured in the absence of inhibitors. Thereafter norepinephrine-induced concentration-response curves were determined in the presence of $\mathrm{Ca}^{2+}$-dependent $\mathrm{Cl}^{-}$channel blocker indanyloxyacetic acid $94\left(\mathrm{R}(+)-\mathrm{IAA}-94\right.$, IAA, $10^{-5} \mathrm{~mol} / \mathrm{L}$, preincubation time $10 \mathrm{~min}$ ) and after $30 \mathrm{~min}$ washing period again in the presence of cyclooxygenase inhibitor indomethacin (IME, $10^{-5} \mathrm{~mol} / \mathrm{L}$, preincubation time $10 \mathrm{~min}$ ). In another group of vessels norepinephrine-induced concentration-response curves were determined in the presence of niflumic acid (NIFLU, $10^{-5} \mathrm{~mol} / \mathrm{L}$, preincubation time $10 \mathrm{~min}$ ) which was used as cyclooxygenase inhibitor and $\mathrm{Ca}^{2+}$-dependent $\mathrm{Cl}^{-}$ channel blocker.

2.4. Drugs and Statistical Analysis. All chemicals were obtained from Sigma (Heidelberg, Germany). R(+)-IAA-94 and niflumic acid were dissolved in ethanol maintaining the final concentration of ethanol in the chamber under $1 \%$. Indomethacin was dissolved in $170 \mathrm{mM} \mathrm{Na}_{2} \mathrm{CO}_{3}$. Logistic model was used for fitting concentration-response curves through the measure values [30]. Pharmacodynamic characteristics-EC50 (half-maximal effective concentration, $\log \mathrm{mol} / \mathrm{L}$ ), $E_{\max }$ (maximal contraction, $\mathrm{mN} / \mathrm{mm}$ ), and slope-were calculated for each norepinephrine-induced concentration-response curve. Data are presented as mean \pm S.E.M. Statistical analysis was performed with one-way ANOVA and post hoc least significant difference test.

\section{Results}

3.1. Basal Characteristics. Blood pressure was higher in SHR than WKY rats without any significant age-dependent increase. The inner diameter of studied femoral arteries was always significantly smaller in SHR than in WKY rats, but it increased with age in both rat strains (Table 1).

3.2. Vascular Responses of Femoral Arteries in Adult and Aged WKY or SHR. The administration of cumulative norepinephrine concentrations to isolated femoral arteries yielded concentration-response curves which were similar in vessels from adult WKY and aged WKY. As far as concentrationresponse curves of SHR arteries are concerned, the maximal contraction $\left(E_{\max }\right)$ was enhanced in vessels from SHR compared to WKY vessels. Ageing increased the maximal contraction in vessels from SHR only (Figure 1; Table 2). Acetylcholine at the concentration $3.10^{-8} \mathrm{~mol} / \mathrm{L}$ relaxed the arteries of adult and aged WKY as well as those of adult SHR by about $50 \%$. The vessels from aged SHR relaxed by $37 \%$ only (Table 3$)$. At the higher concentrations of acetylcholine $\left(10^{-6} \mathrm{~mol} / \mathrm{L}\right.$ in WKY and $3.10^{-6} \mathrm{~mol} / \mathrm{L}$ in SHR $)$ the maximal acetylcholine-induced relaxation of isolated femoral arteries was only slightly attenuated in SHR arteries (Table 3). The wall tension decrease after acetylcholine was greater in SHR vessels, which corresponds to the enhanced arterial contraction in SHR.

3.3. Effect of $\mathrm{Ca}^{2+}$-Dependent $\mathrm{Cl}^{-}$Channels Inhibition on Norepinephrine-Induced Concentration-Response Curves. The inhibition of $\mathrm{Ca}^{2+}$-dependent $\mathrm{Cl}^{-}$channels with IAA almost abolished the norepinephrine-induced contraction of vessels from adult and aged WKY rats and largely reduced the contraction of vessels from adult SHR. The relative inhibitory effect of IAA was surprisingly smallest in femoral arteries isolated from aged SHR (Figure 1; Table 2). The relative contribution of $\mathrm{Ca}^{2+}$-dependent $\mathrm{Cl}^{-}$channel-sensitive component to norepinephrine-induced contraction was $97 \%$ in adult WKY, 90\% in aged WKY, 80\% in adult SHR, but only $55 \%$ in aged SHR. The sensitivity to norepinephrine (EC50) was enhanced and $E_{\max }$ was impaired by IAA pretreatment of WKY vessels compared to the control conditions. In contrast, there were no significant changes in norepinephrine sensitivity of concentration-response curves in SHR vessels (Table 2).

3.4. Effect of $\mathrm{Ca}^{2+}$-Dependent $\mathrm{Cl}^{-}$Channels Inhibition on Norepinephrine-Induced Concentration-Response Curves during NO Synthase Inhibition. The inhibition of NO synthase with L-NNA shifted the concentration-response curves to the left in all groups (Figure 1). $E_{\max }$ was substantially increased as compared to the control conditions (Table 2). In the absence of NO synthesis the inhibition of $\mathrm{Ca}^{2+}$-dependent $\mathrm{Cl}^{-}$channels shifted norepinephrine-induced concentrationresponse curves to the right (Figure 1) and reduced $E_{\max }$ more in WKY than in SHR vessels (Table 2). The relative contribution of $\mathrm{Ca}^{2+}$-dependent $\mathrm{Cl}^{-}$channel-sensitive component represented $93 \%$ in adult WKY and $78 \%$ in aged WKY,but only $63 \%$ in adult SHR and $28 \%$ of norepinephrine-induced contraction in aged SHR. Thus, the effect of IAA was again smallest in aged SHR.

3.5. The Changes between $\mathrm{Ca}^{2+}$-Dependent $\mathrm{Cl}^{-}$Channels and EDCF during Ageing. Norepinephrine-induced contraction of vessels isolated from 20-month-old WKY rats were slightly more sensitive to norepinephrine and reached slightly higher maximal contraction values as compared to adult and aged WKY rats. The acetylcholine-induced relaxation was impaired at low concentration of acetylcholine, but it was not 
TABLE 1: Blood pressure and the diameter of isolated femoral arteries in adult and aged Wistar-Kyoto rats (WKY) and spontaneously hypertensive rats (SHR).

\begin{tabular}{lcccc}
\hline Parameters & $\begin{array}{c}\text { Adult WKY (6 months) } \\
(n=6)\end{array}$ & $\begin{array}{c}\text { Aged WKY (12 months) } \\
(n=7)\end{array}$ & $\begin{array}{c}\text { Adult SHR (6 months) } \\
(n=6)\end{array}$ & $\begin{array}{c}\text { Aged SHR (12 months) } \\
(n=9)\end{array}$ \\
\hline SBP (mm Hg) & $131 \pm 3$ & $134 \pm 4$ & $221 \pm 5^{\mathrm{a}}$ & $215 \pm 6^{\mathrm{c}}$ \\
MAP (mm Hg) & $109 \pm 3$ & $112 \pm 3$ & $182 \pm 5^{\mathrm{a}}$ & $187 \pm 4^{\mathrm{c}}$ \\
DBP (mmHg) & $91 \pm 3$ & $94 \pm 3$ & $152 \pm 4^{\mathrm{a}}$ & $163 \pm 4^{\mathrm{c}}$ \\
Diameter $(\mu \mathrm{m})$ & $995 \pm 21$ & $1052 \pm 20^{\mathrm{a}}$ & $843 \pm 27^{\mathrm{a}}$ & $943 \pm 17^{\mathrm{b}, \mathrm{c}}$ \\
\hline
\end{tabular}

Data are presented as mean \pm S.E.M. SBP: systolic blood pressure; MAP: mean arterial pressure; DBP: diastolic blood pressure. Significant differences: ${ }^{a} P<$ 0.05 versus adult WKY; ${ }^{\mathrm{b}} P<0.05$ versus adult SHR; ${ }^{\mathrm{c}} P<0.05$ versus aged WKY.

changed at higher acetylcholine concentration and reached $79 \pm 2 \%$ of norepinephrine precontraction (Table 3 ).

Surprisingly, the application of $\mathrm{Ca}^{2+}$-dependent $\mathrm{Cl}^{-}$ channel blocker IAA did not impair the norepinephrineinduced contraction as it was shown in our previous experiments with 6- and 12-month-old rats. As in previous experiments with 6- and 12-month-old rats IAA increased EC50, but the $E_{\max }$ was not altered significantly. The subsequent inhibition of cyclooxygenase with indomethacin almost fully abolished the norepinephrine-induced contraction. In parallel experiments the application of niflumic acid, which is considered to be $\mathrm{Ca}^{2+}$-dependent $\mathrm{Cl}^{-}$channel blocker and cyclooxygenase inhibitor, also abolished the norepinephrineinduced contraction to a similar extent as indomethacin. Our experiments have clearly shown that niflumic acid is a potent cyclooxygenase inhibitor, which cannot be used as a simple $\mathrm{Ca}^{2+}$-dependent $\mathrm{Cl}^{-}$channel blocker (Table 4; Figure 2).

\section{Discussion}

We have investigated the effect of ageing and hypertension on the participation of $\mathrm{Ca}^{2+}$-dependent $\mathrm{Cl}^{-}$channels in norepinephrine-induced contraction of femoral arteries. When evaluating $\mathrm{Ca}^{2+}$-dependent $\mathrm{Cl}^{-}$channel-sensitive component of norepinephrine-induced contraction we have demonstrated that the inhibition of $\mathrm{Ca}^{2+}$-dependent $\mathrm{Cl}^{-}$ channels largely impaired the norepinephrine-induced contraction of femoral arteries in all studied groups of rats. Thus, our data are in good agreement with the earlier findings on norepinephrine-induced increase of $\mathrm{Cl}^{-}$conductance in portal vein smooth muscle cells [9]. However, the relative effects were greatest in the arteries of adult WKY rats but smallest in vessels of aged SHR. Our results showed that the contribution of $\mathrm{Ca}^{2+}$-dependent $\mathrm{Cl}^{-}$channels to norepinephrineinduced contraction is reduced during ageing, and hypertension further enhanced this reduction. The mechanism(s) responsible for the residual part of norepinephrine-induced arterial contraction seen mainly in SHR vessels remains to be determined. Resting membrane potential of vascular smooth muscle cells of SHR is increasing during the hypertension development and stays significantly higher compared to normotensive WKY rats [31]. Contrary to our expectations, norepinephrine stimulation of vascular smooth muscle did not open/activate $\mathrm{Ca}^{2+}$-dependent $\mathrm{Cl}^{-}$channels to a larger extent in vascular smooth muscle of SHR.

IAA is a potent $\mathrm{Ca}^{2+}$-dependent $\mathrm{Cl}^{-}$channel inhibitor, but it has also a relatively high affinity to L-VDCC [32]. It is unlikely that IAA affected the L-VDCC significantly in our experiments because a greater IAA effect was disclosed in vessels from adult WKY compared to those from SHR, although L-VDCC plays a more important role in SHR than in WKY [24]. $\mathrm{Ca}^{2+}$-dependent $\mathrm{Cl}^{-}$channels blockers also activate large-conductance $\mathrm{Ca}^{2+}$-activated $\mathrm{K}^{+}$channels [33]. The concentration used in our experiments was lower as assumed for the activation of $\mathrm{Ca}^{2+}$-activated $\mathrm{K}^{+}$channels $\left(10^{-5} \mathrm{~mol} / \mathrm{L}\right.$ versus $\left.5 \times 10^{-4} \mathrm{~mol} / \mathrm{L},[34]\right)$. To our knowledge there is no evidence about decreasing influence of $\mathrm{Ca}^{2+}$ activated $\mathrm{K}^{+}$channels during ageing and further experiments are needed to show if the effect of IAA seen in our study was partially through $\mathrm{Ca}^{2+}$-activated $\mathrm{K}^{+}$channels.Niflumic acid is also a potent cyclooxygenase inhibitor. A comparison of the effect of indomethacin and niflumic acid clearly shows that both compounds are acting through the inhibition of cyclooxygenase pathway because it was impossible to produce additive changes in contraction by the combination of these two compounds.

We have recently demonstrated [35] that a considerable part of norepinephrine-induced contraction of rat femoral artery was mediated by endothelium-derived constricting factor (EDCF). This type of arterial contraction can be largely prevented by the pretreatment of vessels with cyclooxygenase inhibitor indomethacin. Indomethacin administration was also capable of inducing a substantial reduction of the already developed arterial contraction. It is important to note that EDCF contribution to norepinephrine-induced arterial contraction was increasing with age and hypertension development [35]. The same was reported for the role of EDCF in the age-dependent impairment of acetylcholine-induced endothelium-dependent vascular relaxation in developing SHR $[36,37]$. The mechanisms underlying the age-dependent increase of EDCF formation and/or action remain unclear. It can be speculated that the earlier described age-dependent elevation of intracellular $\mathrm{Na}^{+}$concentration could augment cyclooxygenase 2 expression as it was demonstrated in cells with increased $\mathrm{Na}^{+}{ }_{i} / \mathrm{K}^{+}{ }_{i}$ ratio [38]. Nevertheless, it should be mentioned that EDCF participation in vascular contraction elicited by norepinephrine or high doses of acetylcholine 


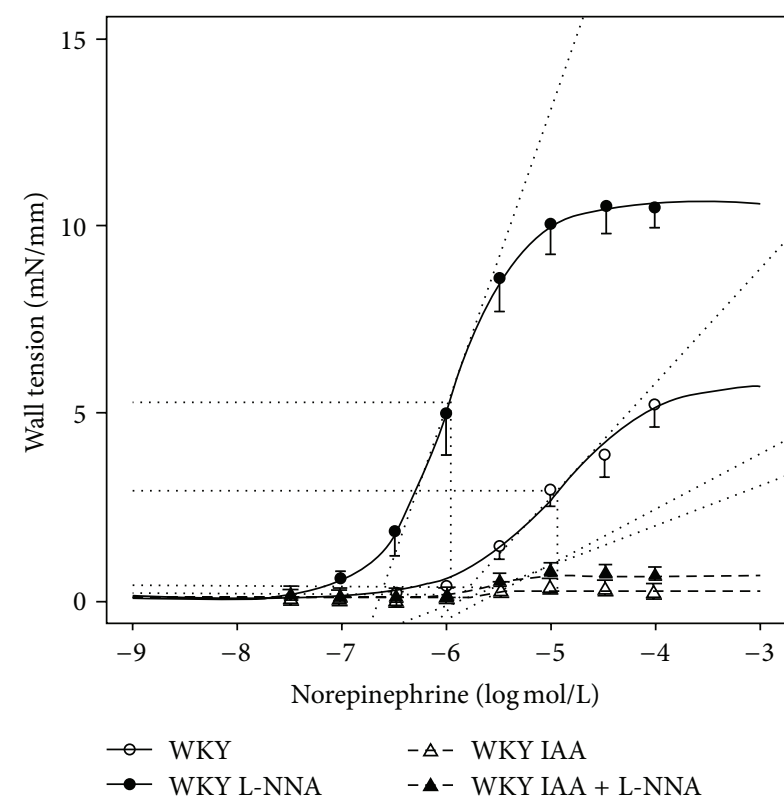

(a)

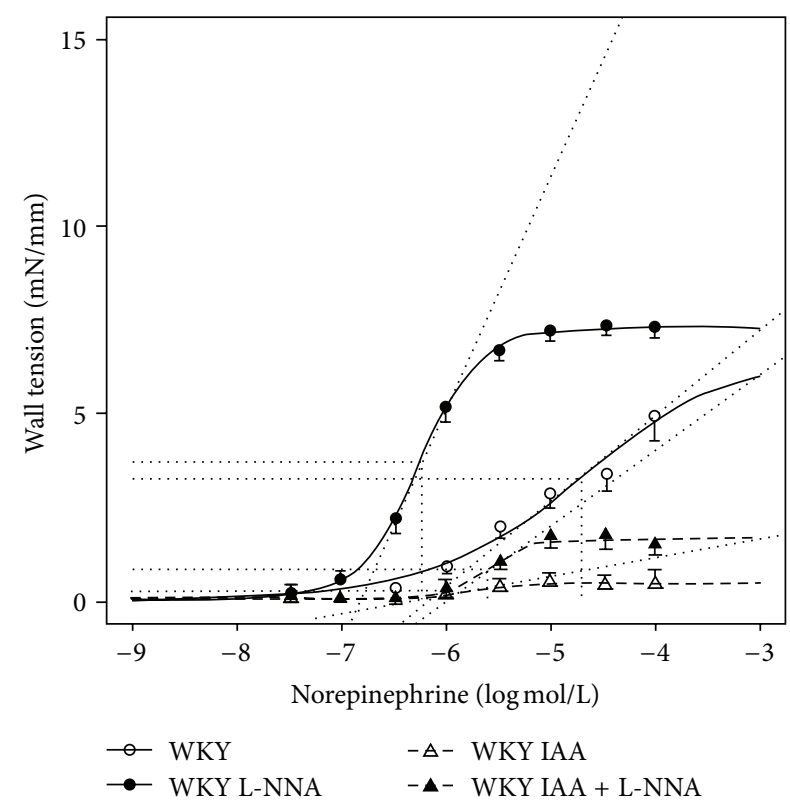

(c)

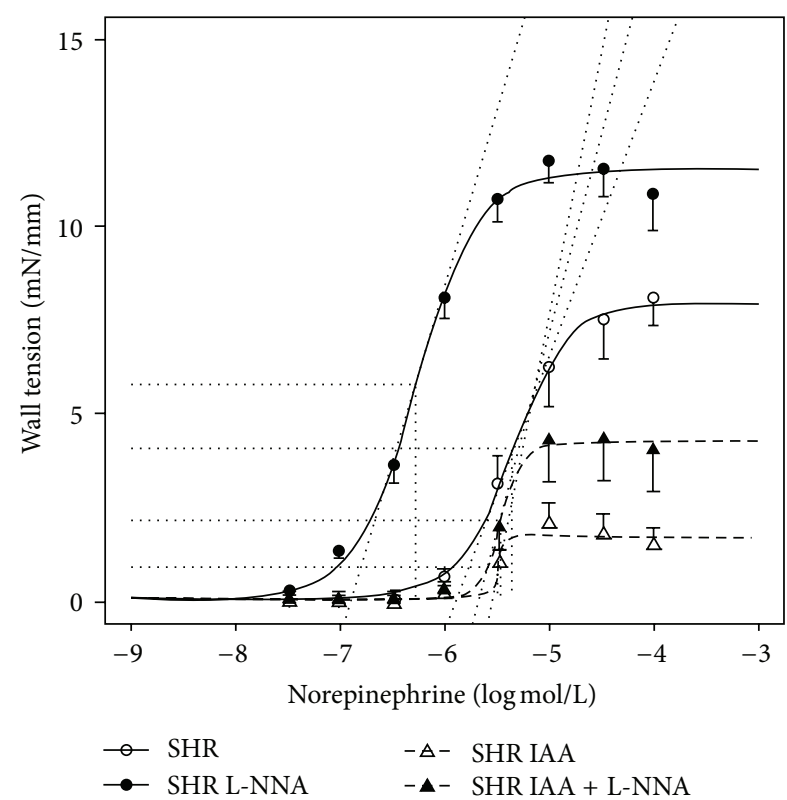

(b)

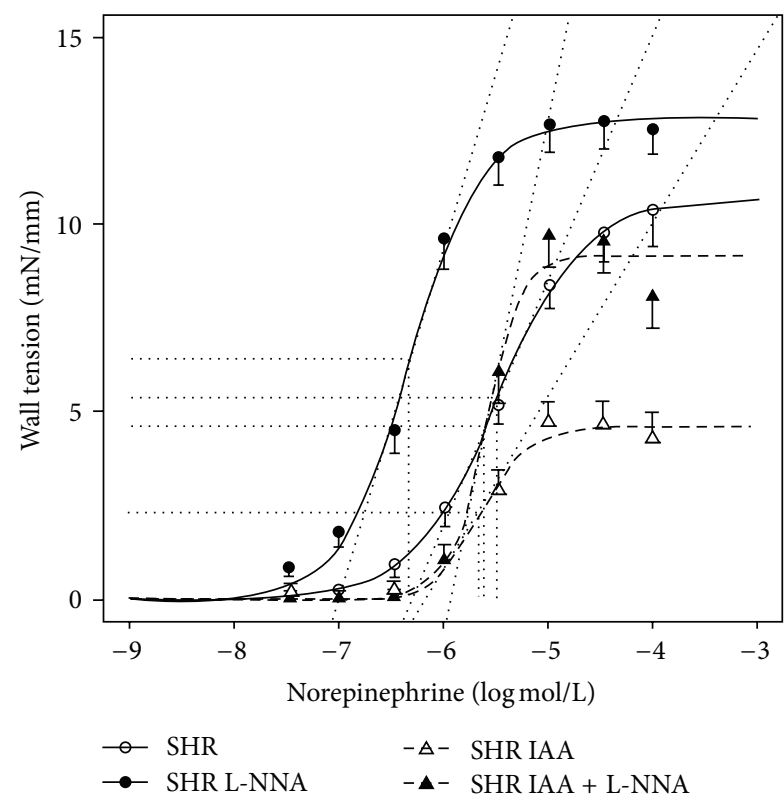

(d)

FIGURE 1: Norepinephrine concentration-response curves obtained in femoral arteries of adult WKY rats (6 months old, (a)), adult SHR (6 months old, (b)), aged WKY rats (12 months old, (c)), and aged SHR (12 months old, (d)) recorded under the control conditions and after the inhibition of NO synthase (L-NNA) or $\mathrm{Ca}^{2+}$-dependent $\mathrm{Cl}^{-}$channels blockade (R(+)-IAA-94, IAA) or both (IAA + L-NNA). Data are presented as mean \pm S.E.M. (for number of vessels see Table 1). Depicted curves were calculated from average values obtained at studied norepinephrine concentrations.

is characteristic for conduit arteries because it is absent in resistance arteries such as small mesenteric vessels [29]. Thus the role of EDCF in blood pressure control remains questionable.

$\mathrm{Ca}^{2+}$-dependent $\mathrm{Cl}^{-}$channels are involved in a major part of norepinephrine-induced contraction of adult and aged WKY arteries, but the contribution of these channels to norepinephrine-induced contraction is decreasing with age and/or hypertension development as was shown using the arteries of 20-month-old WKY rats in which the blockade of $\mathrm{Ca}^{2+}$-dependent $\mathrm{Cl}^{-}$channels was without effect on norepinephrine-induced contraction (Figure 2). This is in contrast with the increasing role of cyclooxygenasesensitive component of norepinephrine-induced contraction during ageing and hypertension [35]. Thus the participation of $\mathrm{Cl}^{-}$channels in norepinephrine-induced arterial 
TABLE 2: Pharmacodynamic parameters of norepinephrine concentration-response curves determined in individual femoral arteries isolated from adult and aged WKY and SHR which were studied under the control conditions (CONTROL), in the presence of $\mathrm{N}^{\omega}$-nitro-L-arginine (L-NNA, NO synthase inhibitor) and in the presence of $\mathrm{R}(+)$-IAA-94 (IAA, $\mathrm{Ca}^{2+}$-dependent $\mathrm{Cl}^{-}$channel blocker) as well as in the presence of IAA and L-NNA (IAA + L-NNA).

\begin{tabular}{lccccc}
\hline & Parameters & Adult WKY (6 months) & Aged WKY (12 months) & Adult SHR (6 months) & Aged SHR (12 months) \\
\hline CONTROL & EC50 (log mol/L) & $-4.93 \pm 0.09$ & $-5.11 \pm 0.13$ & $-5.12 \pm 0.15$ & $-5.43 \pm 0.08$ \\
$(6 / 7 / 6 / 9)$ & $E_{\max }(\mathrm{mN} / \mathrm{mm})$ & $5.26 \pm 0.84$ & $5.30 \pm 0.64$ & $8.25 \pm 0.32^{\mathrm{a}}$ & $10.41 \pm 0.70^{\mathrm{b}, \mathrm{c}}$ \\
& Slope & $3.69 \pm 0.55$ & $3.11 \pm 0.77$ & $11.27 \pm 0.52^{\mathrm{a}}$ & $8.80 \pm 1.10^{\mathrm{c}}$ \\
\hline \multirow{2}{*}{ L-NNA } & EC50 $(\log \mathrm{mol} / \mathrm{L})$ & $-5.84 \pm 0.13^{\mathrm{d}, \mathrm{e}}$ & $-6.14 \pm 0.07^{\mathrm{d}, \mathrm{e}}$ & $-6.17 \pm 0.04^{\mathrm{d}, \mathrm{e}}$ & $-6.28 \pm 0.07^{\mathrm{d}, \mathrm{e}}$ \\
$(6 / 7 / 6 / 7)$ & $E_{\max }(\mathrm{mN} / \mathrm{mm})$ & $10.48 \pm 0.70^{\mathrm{d}, \mathrm{e}}$ & $7.29 \pm 0.30^{\mathrm{a}, \mathrm{d}, \mathrm{e}}$ & $11.31 \pm 0.54^{\mathrm{d}, \mathrm{e}}$ & $12.63 \pm 0.78^{\mathrm{c}, \mathrm{d}, \mathrm{e}}$ \\
& Slope & $10.03 \pm 1.60^{\mathrm{d}}$ & $9.77 \pm 1.84$ & $12.24 \pm 0.46$ & $15.71 \pm 3.12$ \\
\hline IAA & EC50 $(\log \mathrm{mol} / \mathrm{L})$ & $-5.53 \pm 0.13^{\mathrm{d}}$ & $-5.79 \pm 0.13^{\mathrm{d}, \mathrm{e}}$ & $-5.35 \pm 0.05$ & $-5.48 \pm 0.07$ \\
$(6 / 7 / 6 / 9)$ & $E_{\max }(\mathrm{mN} / \mathrm{mm})$ & $0.15 \pm 0.05^{\mathrm{d}}$ & $0.53 \pm 0.08^{\mathrm{d}}$ & $1.68 \pm 0.20^{\mathrm{a}, \mathrm{d}, \mathrm{e}}$ & $4.66 \pm 0.60^{\mathrm{b}, \mathrm{c}, \mathrm{d}, \mathrm{e}}$ \\
& Slope & $2.63 \pm 0.78$ & $1.68 \pm 0.12$ & $9.50 \pm 1.96$ & $21.12 \pm 7.04$ \\
\hline IAA + L-NNA & EC50 (log mol/L) & $-5.42 \pm 0.12^{\mathrm{d}}$ & $-5.47 \pm 0.08^{\mathrm{d}}$ & $-5.28 \pm 0.02$ & $-5.46 \pm 0.07^{\mathrm{b}}$ \\
$(6 / 7 / 6 / 7)$ & $E_{\max }(\mathrm{mN} / \mathrm{mm})$ & $0.76 \pm 0.03^{\mathrm{d}}$ & $1.64 \pm 0.38^{\mathrm{d}}$ & $4.21 \pm 0.52^{\mathrm{a}, \mathrm{d}}$ & $9.17 \pm 0.90^{\mathrm{b}, \mathrm{c}}$ \\
& Slope & $2.00 \pm 0.77$ & $6.29 \pm 3.20$ & $18.40 \pm 4.49^{\mathrm{a}}$ & $14.03 \pm 0.76$ \\
\hline
\end{tabular}

Data are presented as mean \pm S.E.M., the number of vessels studied under different experimental conditions is indicated in parentheses (adult WKY/aged WKY/adult SHR/aged SHR). Significant differences: ${ }^{\mathrm{a}} P<0.05$ versus adult WKY; ${ }^{\mathrm{b}} P<0.05$ versus adult SHR; ${ }^{\mathrm{c}} P<0.05$ versus aged WKY; ${ }^{\mathrm{d}} P<0.05$ versus Control; ${ }^{\mathrm{e}} \mathrm{P}<0.05$ versus IAA + L-NNA.

TABLE 3: Maximal norepinephrine-induced contraction and acetylcholine-induced relaxation of femoral arteries isolated from adult and aged WKY and SHR.

\begin{tabular}{|c|c|c|c|c|c|}
\hline Parameters & $\begin{array}{c}\text { Adult WKY } \\
\text { (6 months) } \\
(n=6)\end{array}$ & $\begin{array}{c}\text { Aged WKY } \\
(12 \text { months }) \\
(n=7)\end{array}$ & $\begin{array}{c}\text { Adult SHR } \\
(6 \text { months }) \\
(n=6)\end{array}$ & $\begin{array}{c}\text { Aged SHR } \\
(12 \text { months }) \\
(n=9)\end{array}$ & $\begin{array}{c}\text { WKY } \\
(20 \text { months }) \\
(n=16)\end{array}$ \\
\hline $\begin{array}{l}\text { Norepinephrine-induced }\left(10^{-4} \mathrm{~mol} / \mathrm{L}\right) \\
\text { maximal contraction }(\mathrm{mN} / \mathrm{mm})\end{array}$ & $5.26 \pm 0.84$ & $5.30 \pm 0.64$ & $8.25 \pm 0.32^{\mathrm{a}}$ & $10.41 \pm 0.70^{\mathrm{a}, \mathrm{b}}$ & $6.79 \pm 0.20$ \\
\hline $\begin{array}{l}\text { Acetylcholine-induced }\left(3.10^{-8} \mathrm{~mol} / \mathrm{L}\right) \\
\text { relaxation }(\%)\end{array}$ & $53 \pm 3$ & $47 \pm 6$ & $55 \pm 4$ & $37 \pm 4^{\mathrm{a}, \mathrm{b}}$ & $18 \pm 4^{\mathrm{c}}$ \\
\hline $\begin{array}{l}\text { Acetylcholine-induced }\left(3.10^{-8} \mathrm{~mol} / \mathrm{L}\right) \\
\text { wall tension decrease }(\mathrm{mN} / \mathrm{mm})\end{array}$ & $-2.70 \pm 0.36$ & $-2.02 \pm 0.41$ & $-4.37 \pm 0.70^{(\mathrm{a})}$ & $-4.18 \pm 0.55^{\mathrm{a}}$ & $-0.98 \pm 0.22^{c}$ \\
\hline Acetylcholine-induced relaxation $(\%)^{*}$ & $85 \pm 4$ & $82 \pm 5$ & $67 \pm 4^{\mathrm{a}}$ & $70 \pm 2$ & $79 \pm 2$ \\
\hline $\begin{array}{l}\text { Acetylcholine-induced wall tension } \\
\text { decrease }(\mathrm{mN} / \mathrm{mm})^{*}\end{array}$ & $-4.37 \pm 0.65$ & $-3.49 \pm 0.44$ & $-5.30 \pm 0.38$ & $-8.04 \pm 0.84^{\mathrm{a}, \mathrm{b}}$ & $-4.70 \pm 0.23$ \\
\hline
\end{tabular}

Data are presented as mean \pm S.E.M.; ${ }^{\mathrm{a}} P<0.05$ versus aged-matched WKY; ${ }^{\mathrm{b}} P<0.05$ versus adult $\mathrm{SHR} ;{ }^{\mathrm{c}} P<0.05$ versus WKY; ${ }^{(\mathrm{a})}$ represents borderline significance $P<0.08$. * Maximal acetylcholine-induced relaxations were achieved in femoral arteries of WKY at the concentration $10^{-6} \mathrm{~mol} / \mathrm{L}$ and in femoral arteries of SHR at the concentration $3 \cdot 10^{-6} \mathrm{~mol} / \mathrm{L}$.

contraction was drastically reduced in aged SHR compared to adult animals, but it was not found in arteries of 20-month-old WKY rats. It seems that the role of $\mathrm{Ca}^{2+}$-dependent $\mathrm{Cl}^{-}$channels is replaced by the increasing influence of EDCF (cyclooxygenase-sensitive component of norepinephrine-induced contraction). It remains to be determined which other cyclooxygenase-sensitive mechanism is responsible for the progressive age-dependent augmentation of norepinephrine-induced contraction of large arteries in ageing and hypertension.

In contrast to the lack of effects of $\mathrm{Ca}^{2+}$-dependent $\mathrm{Cl}^{-}$ channel inhibition, the inhibition of cyclooxygenase with indomethacin led to the attenuation of norepinephrineinduced contraction of femoral arteries of 20-month-old WKY rats. In parallel experiments with vessels of these old rats, the application of niflumic acid led to the attenuation of norepinephrine-induced contraction as well. Niflumic acid is considered to be a $\mathrm{Ca}^{2+}$-dependent $\mathrm{Cl}^{-}$channel inhibitor as well as cyclooxygenase inhibitor. Our experiments clearly indicated that niflumic acid is a potent cyclooxygenase inhibitor and that the results obtained with niflumic acid in other studies should be considered carefully. Unfortunately, we were not able to investigate the effect of niflumic acid after the administration of indomethacin on norepinephrineinduced contraction because indomethacin alone almost abolished the contraction to norepinephrine.

The inhibition of NO synthesis pronounced the ageand hypertension-dependent reduction of $\mathrm{Ca}^{2+}$-dependent $\mathrm{Cl}^{-}$channel-sensitive component of norepinephrine-induced contraction. It is possible that the endothelial factors (such as NO) might contribute to the reduction of IAA-sensitive component of norepinephrine-induced contraction. Further 
TABLE 4: Pharmacodynamic parameters of norepinephrine concentration-response curves determined in individual femoral arteries isolated from 20-month-old WKY rats in the presence of $\mathrm{R}(+)$-IAA-94 (IAA, $\mathrm{Ca}^{2+}$-dependent $\mathrm{Cl}^{-}$channel blocker) and indomethacin (IME, cyclooxygenase inhibitor) as well as in the presence of niflumic acid (NIFLU, cyclooxygenase inhibitor, and $\mathrm{Cl}^{-}$channel blocker).

\begin{tabular}{cccccc}
\hline & Parameters & Control $(n=16)$ & IAA $(n=8)$ & IME $(n=8)$ & NIFLU $(n=8)$ \\
\hline \multirow{3}{*}{ WKY } & EC50 $(\log \mathrm{mol} / \mathrm{L})$ & $-5.22 \pm 0.12$ & $-5.89 \pm 0.10^{\mathrm{a}}$ & $-4.67 \pm 0.18^{\mathrm{b}}$ & $-4.93 \pm 0.18^{\mathrm{b}}$ \\
& $E_{\max }(\mathrm{mN} / \mathrm{mm})$ & $6.79 \pm 0.20$ & $6.86 \pm 0.26$ & $1.40 \pm 0.10^{\mathrm{a}, \mathrm{b}}$ & $1.18 \pm 0.06^{\mathrm{a}, \mathrm{b}}$ \\
& Slope & $3.90 \pm 0.37$ & $4.49 \pm 0.35$ & $0.43 \pm 0.10^{\mathrm{a}, \mathrm{b}}$ & $0.63 \pm 0.09^{\mathrm{a}, \mathrm{b}}$ \\
\hline
\end{tabular}

Data are presented as mean \pm S.E.M.; ${ }^{\mathrm{a}} P<0.05$ versus control; ${ }^{\mathrm{b}} P<0.05$ versus IAA.

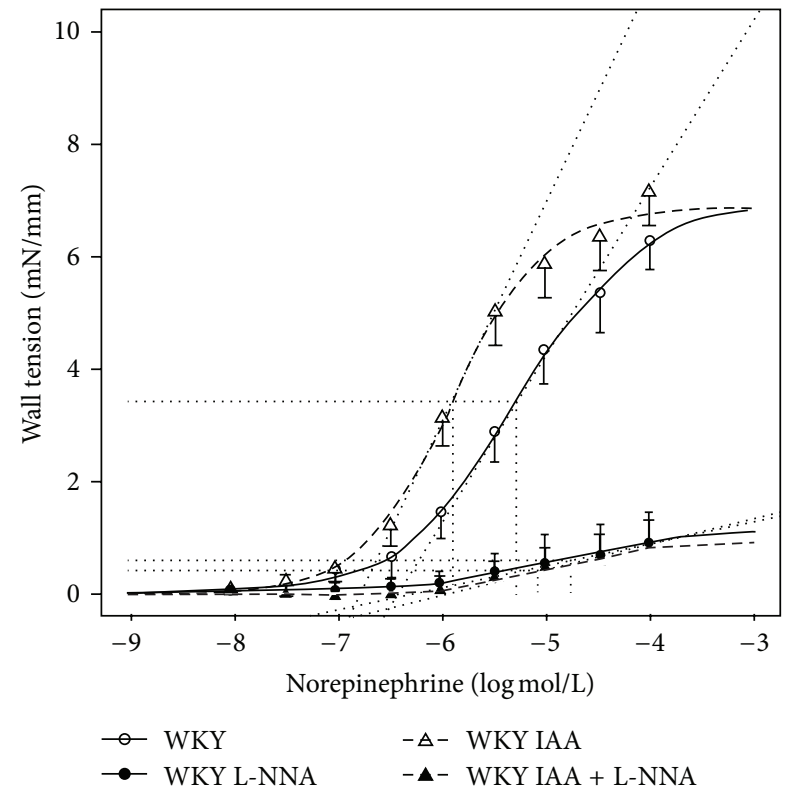

FIGURE 2: Norepinephrine concentration-response curves obtained in femoral arteries of 20 -month-old WKY rats (WKY) recorded under the control conditions and after $\mathrm{Ca}^{2+}$-dependent $\mathrm{Cl}^{-}$channels blockade (R(+)-IAA-94, IAA) or after the inhibition of cyclooxygenase (indomethacin, IME) or in the presence of niflumic acid (NIFLU). Data are presented as mean \pm S.E.M. (for number of vessels see Table 4). Depicted curves were calculated from average values obtained at studied norepinephrine concentrations.

studies with more specific compounds are needed to separate the $\mathrm{Cl}^{-}$current dependent on $\mathrm{NO}$ as shown by Matchkov et al. [17] and Boedtkjer et al. [18] from the $\mathrm{Ca}^{2+}$-dependent $\mathrm{Cl}^{-}$ current in vascular smooth muscle cells.

It is important to note that the inhibition of $\mathrm{Ca}^{2+}$ dependent $\mathrm{Cl}^{-}$channels was suggested as a possible therapeutic target in hypertension [39]. In the present study we provide the first evidence that the activation/opening of $\mathrm{Ca}^{2+}$ dependent $\mathrm{Cl}^{-}$channels is important for the maintenance of normal physiological state during norepinephrine-induced contraction, at least in femoral arteries. Further attention should be paid to the interactions of $\mathrm{Cl}^{-}$channels with other ion transporter systems. Recent data indicate that $\mathrm{Cl}^{-}$ channels in vascular smooth muscle cells are under the control of inwardly directed $\mathrm{Na}^{+}, \mathrm{K}^{+}$, and $2 \mathrm{Cl}^{-}$cotransport (NKCC1). Numerous research groups demonstrated that the inhibitors of this carrier such as bumetanide and furosemide sharply diminished contraction of blood vessels elicited by norepinephrine or other vasoconstrictors (for review see [40]). Increased $n k c c 1$ mRNA expression and $\mathrm{NKCC1}$ protein content in the aorta of SHR was accompanied by hypomethylation of the $n k c c 1$ gene promoter [41]. It is important to note that the methylation of $n k c c 1$ promoter in normotensive WKY rats was increased with age, whereas in SHR it remained hypomethylated after hypertension development. Both increased $n k c c l$ expression and inhibitory action of bumetanide on mesenteric artery contractions were increased with age in SHR but not in WKY rats [42]. It would therefore be desirable to study the effects of $\mathrm{Ca}^{2+}$-dependent $\mathrm{Cl}^{-}$channel blockers on norepinephrine-induced vascular contraction in the presence of NKCC1 inhbitors.

In conclusion, our study demonstrated a considerable contribution of $\mathrm{Ca}^{2+}$-dependent $\mathrm{Cl}^{-}$channels to norepinephrine-induced arterial contraction, which diminishes with age, hypertension development, and/or inhibition of NO synthesis. Further studies are needed to provide the evidence for our hypothesis that $\mathrm{Ca}^{2+}$-dependent $\mathrm{Cl}^{-}$channels are important for the maintenance of normal physiological state in the vascular system. The loss or inactivation of these channels during ageing and/or hypertension development could be seen as a pathological mechanism.

\section{Limitations of the Study}

The contribution of $\mathrm{Ca}^{2+}$-dependent $\mathrm{Cl}^{-}$channels in norepinephrine-induced arterial contraction should be investigated in young normotensive and genetically hypertensive rats to reveal their potential role in the development of hypertension. The contribution of these ion channels to arterial contraction elicited by other vasoconstrictors (such as angiotensin II or endothelin-1) should also be studied. It would be desirable to evaluate the above mechanism in other forms of experimental hypertension.

\section{Conflict of Interests}

The authors declare that there is no conflict of interests regarding the publication of this paper.

\section{Acknowledgments}

Skilled assistance of Iva Nahodilová is greatly appreciated. This work was partially supported by the research Grants of 
Czech Science Foundation (GACR 304/12/0259) and AV0Z 50110509.

\section{References}

[1] A. P. Somlyo and B. Himpens, "Cell calcium and its regulation in smooth muscle," FASEB Journal, vol. 3, no. 11, pp. 2266-2276, 1989.

[2] H. Karaki, H. Ozaki, M. Hori et al., "Calcium movements, distribution, and functions in smooth muscle," Pharmacological Reviews, vol. 49, no. 2, pp. 157-230, 1997.

[3] M. J. Berridge, "Smooth muscle cell calcium activation mechanisms," Journal of Physiology, vol. 586, no. 21, pp. 5047-5061, 2008.

[4] J. E. Brayden and M. T. Nelson, "Regulation of arterial tone by activation of calcium-dependent potassium channels," Science, vol. 256, no. 5056, pp. 532-535, 1992.

[5] S. Lišková, M. Petrová, P. Karen, J. Kuneš, and J. Zicha, “Influence of calcium-dependent potassium channel blockade and nitric oxide inhibition on norepinephrine-induced contractions in two forms of genetic hypertension," Journal of the American Society of Hypertension, vol. 4, no. 3, pp. 128-134, 2010.

[6] R. Casteels, K. Kitamura, H. Kuriyama, and H. Suzuki, “The membrane properties of the smooth muscle cells of the rabbit main pulmonary artery," Journal of Physiology, vol. 271, no. 1, pp. 41-61, 1977.

[7] K. Kitamura and J. Yamazaki, "Chloride channels and their functional roles in smooth muscle tone in the vasculature," Japanese Journal of Pharmacology, vol. 85, no. 4, pp. 351-357, 2001.

[8] N. S. Pollock, M. E. Kargacin, and G. J. Kargacin, "Chloride channel blockers inhibit $\mathrm{Ca}^{2+}$ uptake by the smooth muscle sarcoplasmic reticulum," Biophysical Journal, vol. 75, no. 4, pp. 1759-1766, 1998.

[9] P. Pacaud, G. Loirand, C. Mironneau, and J. Mironneau, "Noradrenaline activates a calcium-activated chloride conductance and increases the voltage-dependent calcium current in cultured single cells of rat portal vein," British Journal of Pharmacology, vol. 97, no. 1, pp. 139-146, 1989.

[10] W. A. Large and Q. Wang, "Characteristics and physiological role of the $\mathrm{Ca}^{2+}$-activated $\mathrm{Cl}^{-}$conductance in smooth muscle," American Journal of Physiology, vol. 271, no. 2, pp. C435-C454, 1996.

[11] D. F. Van Helden, "An $\alpha$-adrenoceptor-mediated chloride conductance in mesenteric veins of the guinea-pig," Journal of Physiology, vol. 401, pp. 489-501, 1988.

[12] U. Klockner and G. Isenberg, "Endothelin depolarizes myocytes from porcine coronary and human mesenteric arteries through a Ca-activated chloride current," Pflugers Archiv, vol. 418, no. 12, pp. 168-175, 1991.

[13] A. J. Fuller, B. C. Hauschild, R. Gonzalez-Villalobos et al., "Calcium and chloride channel activation by angiotensin II$\mathrm{AT}_{1}$ receptors in preglomerular vascular smooth muscle cells," American Journal of Physiology, vol. 289, no. 4, pp. F760-F767, 2005.

[14] P. Pacaud, G. Loirand, A. Baron, C. Mironneau, and J. Mironneau, " $\mathrm{Ca}^{2+}$ channel activation and membrane depolarization mediated by $\mathrm{Cl}^{-}$channels in response to noradrenaline in vascular myocytes," British Journal of Pharmacology, vol. 104, no. 4, pp. 1000-1006, 1991.
[15] Y. Hirakawa, M. Gericke, R. A. Cohen, and V. M. Bolotina, " $\mathrm{Ca}^{2+}$-dependent $\mathrm{Cl}^{-}$channels in mouse and rabbit aortic smooth muscle cells: regulation by intracellular $\mathrm{Ca}^{2+}$ and NO," American Journal of Physiology, vol. 277, no. 5, pp. H1732H1744, 1999.

[16] J. E. Graves, I. A. Greenwood, and W. A. Large, "Tonic regulation of vascular tone by nitric oxide and chloride ions in rat isolated small coronary arteries," American Journal of Physiology, vol. 279, no. 6, pp. H2604-H2611, 2000.

[17] V. V. Matchkov, C. Aalkjaer, and H. Nilsson, "A cyclic GMPdependent calcium-activated chloride current in smoothmuscle cells from rat mesenteric resistance arteries," Journal of General Physiology, vol. 123, no. 2, pp. 121-134, 2004.

[18] D. M. B. Boedtkjer, V. V. Matchkov, E. Boedtkjer, H. Nilsson, and C. Aalkjaer, "Vasomotion has chloride-dependency in rat mesenteric small arteries," Pflugers Archiv, vol. 457, no. 2, pp. 389-404, 2008.

[19] M. Pintérová, J. Kuneš, and J. Zicha, "Altered neural and vascular mechanisms in hypertension," Physiological Research, vol. 60, pp. 381-402, 2011.

[20] Y. Shirasaki, C. Su, and T. J.-F. Lee, "Endothelial modulation of vascular relaxation to nitrovasodilators in aging and hypertension," Journal of Pharmacology and Experimental Therapeutics, vol. 239, no. 3, pp. 861-866, 1986.

[21] F. Li and I. G. Joshua, "Decreased arteriolar endotheliumderived relaxing factor production during the development of genetic hypertension," Clinical and Experimental Hypertension, vol. 15, no. 3, pp. 511-526, 1993.

[22] S. Fujimoto, Y. Dohi, and K. Aoki, "Diminished $\beta$-adrenoceptor-mediated relaxation of arteries from spontaneously hypertensive rats before and during development of hypertension," European Journal of Pharmacology, vol. 136, no. 2, pp.179187, 1987.

[23] S. Arribas, J. Marin, A. Ponte, G. Balfagon, and M. Salaices, "Norepinephrine-induced relaxations in rat aorta mediated by endothelial beta adrenoceptors. Impairment by ageing and hypertension," Journal of Pharmacology and Experimental Therapeutics, vol. 270, no. 2, pp. 520-527, 1994.

[24] N. J. Rusch and K. Hermsmeyer, "Calcium currents are altered in the vascular muscle cell membrane of spontaneously hypertensive rats," Circulation Research, vol. 63, no. 6, pp. 997-1002, 1988.

[25] R. H. Cox and I. M. Lozinskaya, "Augmented calcium currents in mesenteric artery branches of the spontaneously hypertensive rats," Hypertension, vol. 26, no. 6, pp. 1060-1064, 1995.

[26] L. Paulis, S. Líšková, M. Pintérová, Z. Dobešová, J. Kuneš, and J. Zicha, "Nifedipine-sensitive noradrenergic vasoconstriction is enhanced in spontaneously hypertensive rats: the influence of chronic captopril treatment," Acta Physiologica, vol. 191, pp. 255-266, 2007.

[27] M. Pintérová, S. Líšková, Z. Dobešová, M. Behuliak, J. Kuneš, and J. Zicha, "Impaired control of L-type voltage-dependent calcium channels in experimental hypertension," Physiological Research, vol. 58, supplement 2, pp. S43-S54, 2009.

[28] M. Pintérová, P. Karen, J. Kuneš, and J. Zicha, "Role of nifedipine-sensitive sympathetic vasoconstriction in maintenance of high blood pressure in spontaneously hypertensive rats: effect of Gi-protein inactivation by pertussis toxin," Journal of Hypertension, vol. 28, no. 5, pp. 969-978, 2010. 
[29] L. Paulis, J. Zicha, J. Kunes et al., "Regression of L-NAMEinduced hypertension: the role of nitric oxide and endotheliumderived constricting factor," Hypertension Research, vol. 31, no. 4, pp. 793-803, 2008.

[30] J. Janáček and I. Prášil, "Quantification of plant frost injury by nonlinear fitting of an S-shaped function," Cryoletters, vol. 12, pp. 47-52, 1991.

[31] D. W. Cheung, "Membrane potential of vascular smooth muscle and hypertension in spontaneously hypertensive rats," Canadian Journal of Physiology and Pharmacology, vol. 62, no. 8, pp. 957-960, 1984.

[32] J. M. Doughty, A. L. Miller, and P. D. Langton, "Non-specificity of chloride channel blockers in rat cerebral arteries: block of the L-type calcium channel," Journal of Physiology, vol. 507, no. 2, pp. 433-439, 1998.

[33] I. A. Greenwood and N. Leblanc, "Overlapping pharmacology of $\mathrm{Ca}^{2+}$-activated $\mathrm{Cl}^{-}$and $\mathrm{K}^{+}$channels," Trends in Pharmacological Sciences, vol. 28, no. 1, pp. 1-5, 2007.

[34] C. Toma, I. A. Greenwood, R. M. Helliwell, and W. A. Large, "Activation of potassium currents by inhibitors of calciumactivated chloride conductance in rabbit portal vein smooth muscle cells," British Journal of Pharmacology, vol. 118, no. 3, pp. 513-520, 1996.

[35] S. Líšková, M. Petrová, K. Petr, J. Kuneš, and J. Zicha, "Effects of aging and hypertension on the participation of endotheliumderived constricting factor (EDCF) in norepinephrine-induced contraction of rat femoral artery," European Journal of Pharmacology, vol. 667, no. 1-3, pp. 265-270, 2011.

[36] P. A. C. Watt and H. Thurston, "Endothelium-dependent relaxation in resistance vessels from the spontaneously hypertensive rats," Journal of Hypertension, vol. 7, no. 8, pp. 661-666, 1989.

[37] T. Koga, Y. Takata, K. Kobayashi, S. Takishita, Y. Yamashita, and M. Fujishima, "Age and hypertension promote endotheliumdependent contractions to acetylcholine in the aorta of the rat," Hypertension, vol. 14, no. 5, pp. 542-548, 1989.

[38] S. V. Koltsova, Y. Trushina, M. Haloui et al., "Ubiquitous $\left[\mathrm{Na}^{+}\right]_{\mathrm{i}} /\left[\mathrm{K}^{+}\right]_{\mathrm{i}}$-sensitive transcriptome in mammalian cells: evidence for $\mathrm{Ca}^{2+}{ }_{\mathrm{i}}$-independent excitation-transcription coupling," PLoS ONE, vol. 7, Article ID e38032, 2012.

[39] K. Goto, F. R. Edwards, and C. E. Hill, "Depolarization evoked by acetylcholine in mesenteric arteries of hypertensive rats attenuates endothelium-dependent hyperpolarizing factor," Journal of Hypertension, vol. 25, no. 2, pp. 345-359, 2007.

[40] S. N. Orlov, S. V. Koltsova, J. Tremblay, M. B. Baskakov, and P. Hamet, "NKCC1 and hypertension: role in the regulation of vascular smooth muscle contractions and myogenic tone," Annals of Medicine, vol. 44, supplement 1, pp. S111-S118, 2012.

[41] H.-A. Lee, I. Baek, Y. M. Seok et al., "Promoter hypomethylation upregulates $\mathrm{Na}^{+}-\mathrm{K}^{+}-2 \mathrm{Cl}^{-}$cotransporter 1 in spontaneously hypertensive rats," Biochemical and Biophysical Research Communications, vol. 396, no. 2, pp. 252-257, 2010.

[42] H.-M. Cho, H.-A. Lee, H. Y. Kim, H. S. Han, and I. K. Kim, "Expression of $\mathrm{Na}^{+}-\mathrm{K}^{+}-2 \mathrm{Cl}$ cotransporter 1 is epigenetically regulated during postnatal development of hypertension," American Journal of Hypertension, vol. 24, no. 12, pp. 1286-1293, 2011. 


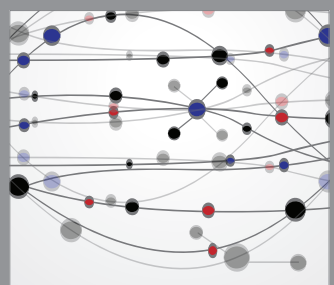

The Scientific World Journal
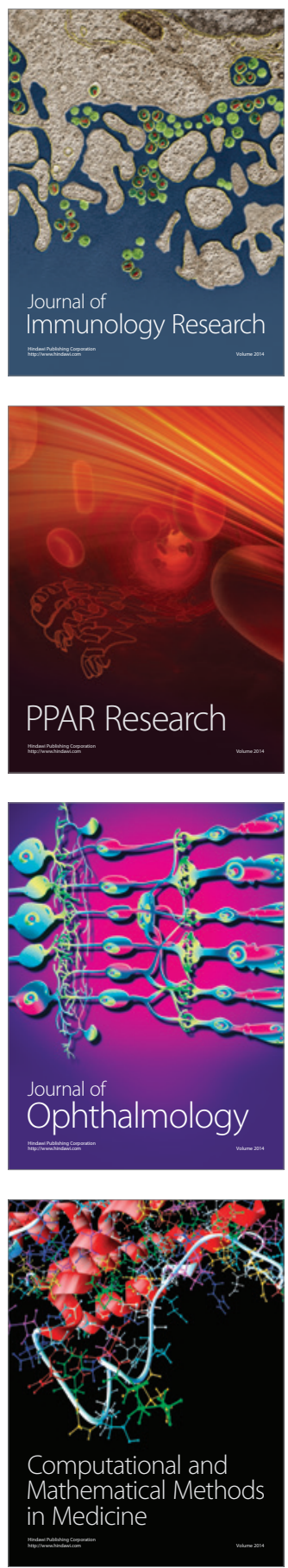

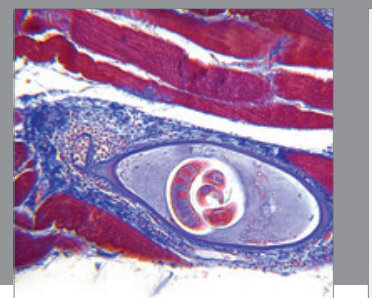

Gastroenterology

Research and Practice
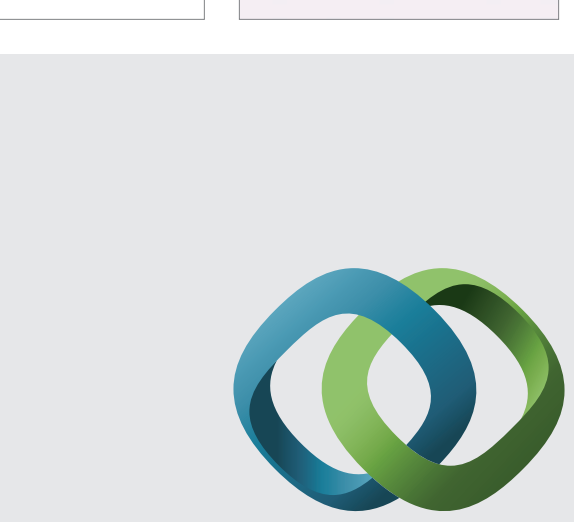

\section{Hindawi}

Submit your manuscripts at

http://www.hindawi.com
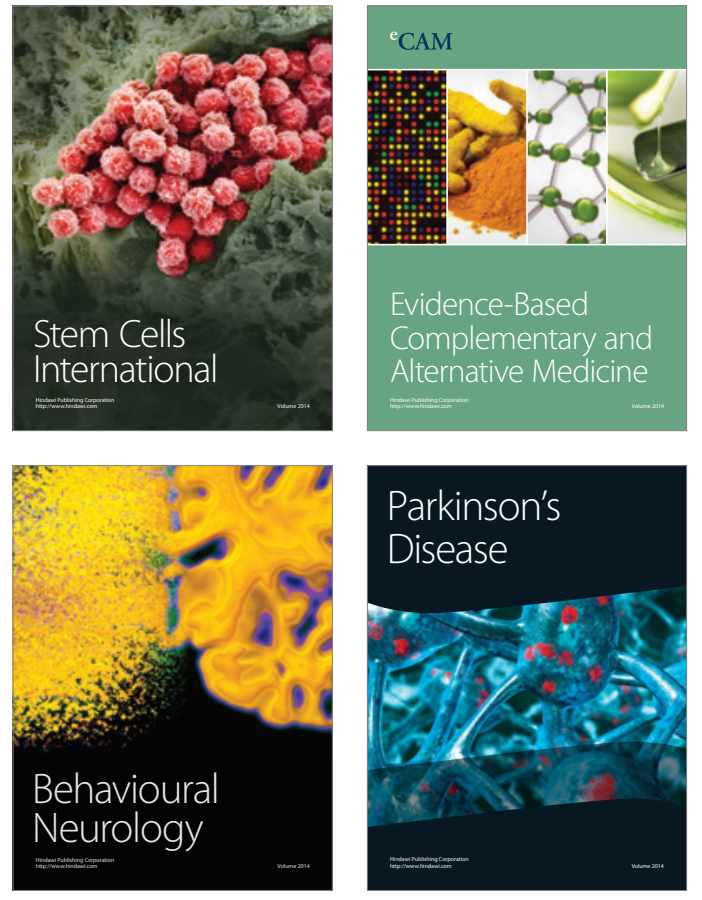
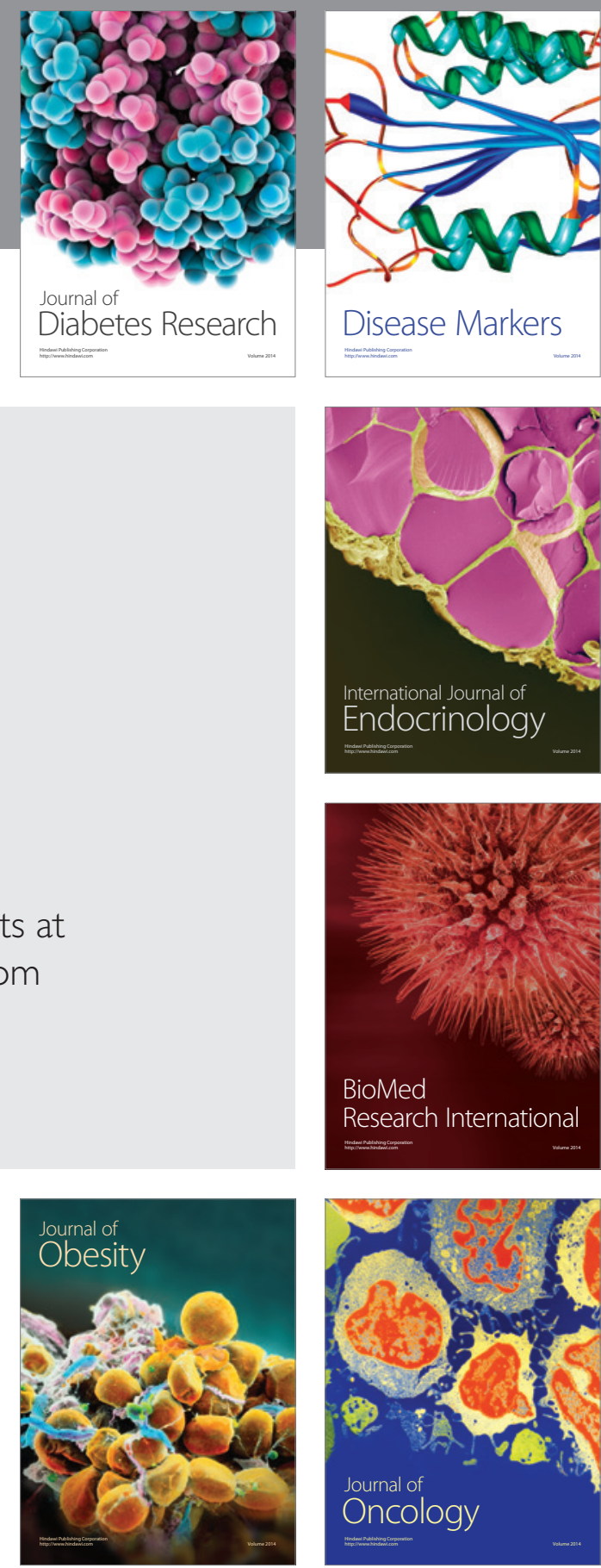

Disease Markers
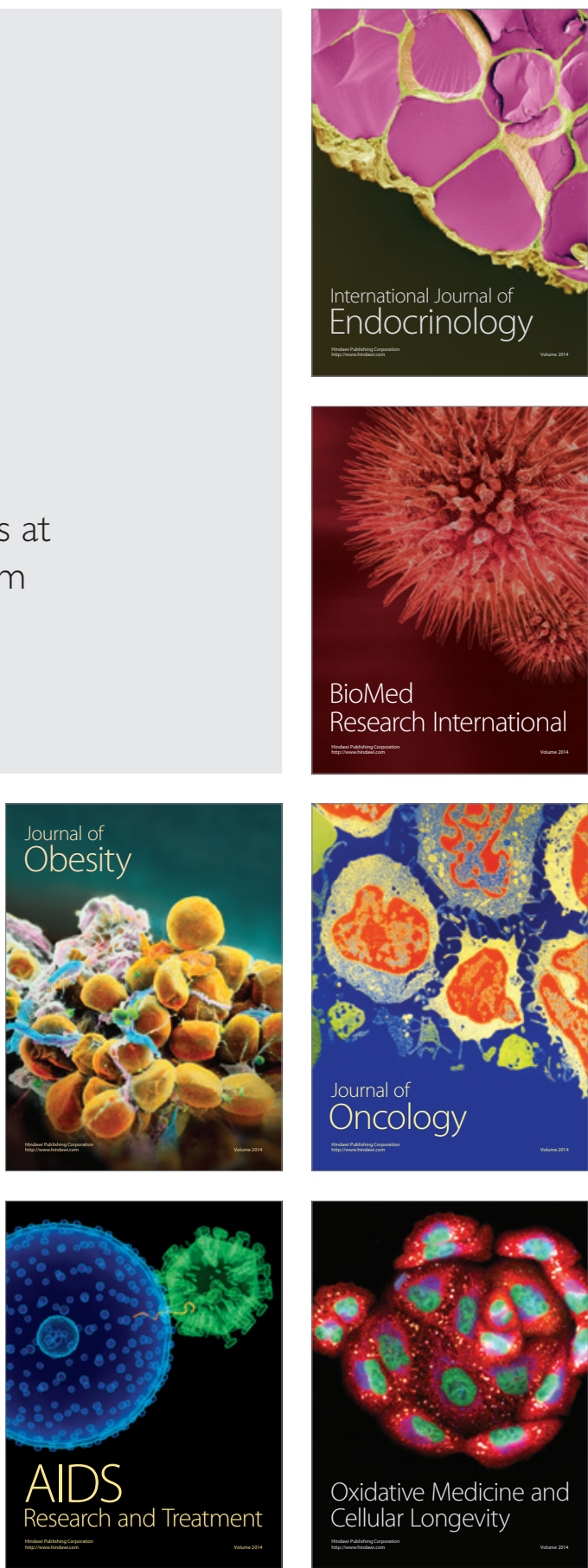